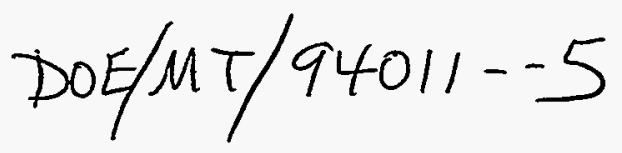

\author{
STUDY OF THE EFFECTS OF AMBIENT CONDITIONS UPON THE \\ PERFORMANCE OF FAN POWERED, INFRARED, NATURAL GAS BURNERS
}

Quarterly Technical Progress Report

For the Period July 1, 1995 -- September 30, 1995

Tiejun Bai (PI), Yaw D. Yeboah, and Ramanathan Sampath

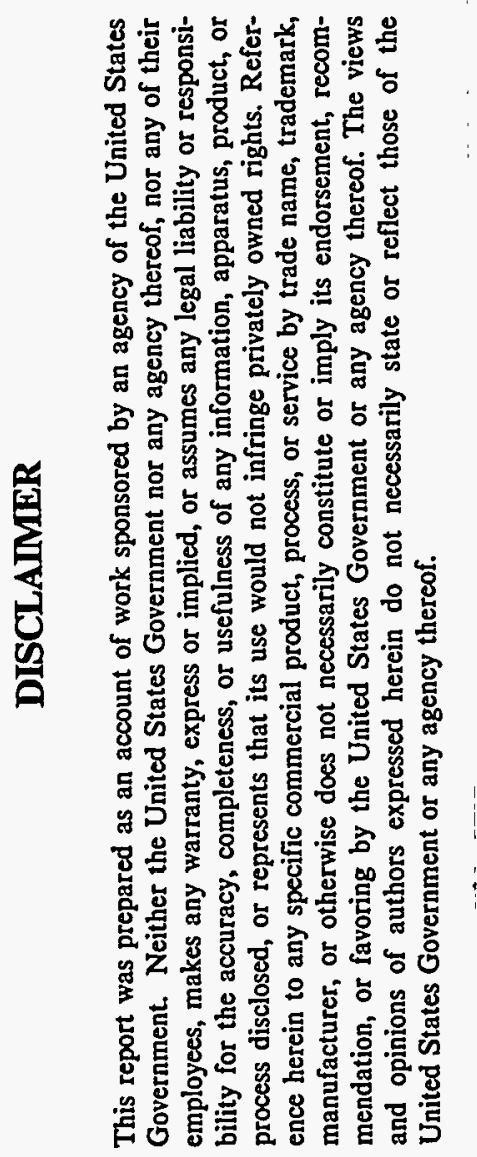

October 1995

Grant No. DE-FG22-94MT94011

For

U.S. Department of Energy

Pittsburgh Energy Technology Center

Attn: Document Control Center

P.O. Box 10940, MS 921-143

Pittsburgh, PA 15236-0940

By

Department of Engineering

Clark Atlanta University

Atlanta, GA 30314

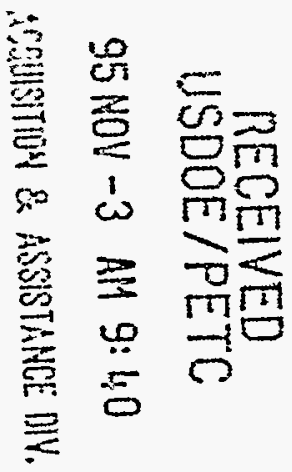

US/DOE PATENT CLEARANCE IS NOT REQUIRED PRIOR TO THE PUBLICATION OF THIS DOCUMENT 
TABLE OF CONTENTS

page

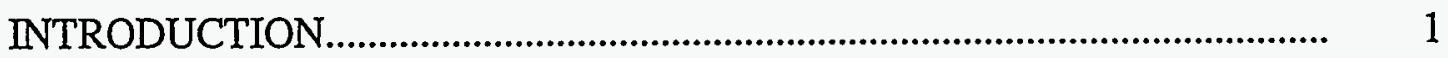

PROGRESS TO DATE ...............................................................................

DEVELOPMENT OF THE EXPERIMENTAL FACILITIES ................. 2

PIR BURNER PERFORMANCE MODEL DEVELOPMENT................... 4

PLANS FOR THE NEXT QUARTER ..............................................................

SUMMARY AND CONCLUSIONS................................................................. 8

NOMENCLATURE................................................................................... 8

REFERENCES................................................................................. 9 


\section{STUDY OF THE EFFECTS OF AMBIENT CONDITIONS UPON THE PERFORMANCE OF FAN POWERED, INFRARED, NATURAL GAS BURNERS}

\section{INTRODUCTION}

This quarterly technical progress report describes work performed under DOE Grant No. DE-FG22-94MT94011 during the period July 1, 1995 to September 30, 1995 which covers the fourth quarter of the project. The objective of this investigation is to characterize the operation of fan powered infrared burner (PIR) at various gas compositions and ambient conditions and develop design guidelines for appliances containing PIR burners for satisfactory performance.

The fan powered infrared burner is a technology introduced more recently in the residential and commercial markets. It is a surface combustor that elevates the temperature of the burner head to a radiant condition. A variety of metallic and ceramic materials are used for the burner heads. It has been demonstrated that infrared burners produce low $\mathrm{CO}$ and $\mathrm{NO}_{\mathrm{x}}$ emissions in a controlled geometric space. As the environmental regulations become more stringent, infrared burners are receiving increasing interests.

In this program, an experimental setup will be devised and built. The experimental rig will be capable of measuring the combustion product output, as well as providing a means by which the radiant heat output of the porous infrared burner can be measured. The burner is selected from an existing commercial appliance that is compatible with the laboratory facilities in the Combustion Laboratory at Clark Atlanta University. The theoretical basis for the behavior of PIR burners to the change in ambient conditions and fuel compositions will be established through analysis of the heat transfer ' between the burner and gas. The model will also be modified and improved through comparison with experimental results.

During this period, experimental setup with optical and electronic instrumentation that is necessary for measuring the radiant heat output and the emission gas output of the burner has been established. The radiation measurement instrument, an FTIR, has been purchased and installed in the porous burner experimental system. The radiation measurement capability of the FTIR was tested and found to be satisfactory. A standard blackbody source, made by Graseby Infrared, was employed to calibrate the FTIR. A collection duct for emission gas measurement was fabricated and connected to the existing Horiba gas analyzer. Test runs are being conducted for flue gas analysis. A number of published research papers on modeling of porous burners were reviewed. The physical mechanism and theoretical analysis of the combustion process of the PIR burner was formulated. The numerical modeling and implementation of a PIR burner code at CAU's computing facility is in progress. 


\section{PROGRESS TO DATE}

This report covers the fourth quarter of the project. The infrared burner has been installed in the CAU's combustion laboratory and proper instrumentation including fuel/air flowrate measurement, exhaust gas emission measurement, and radiation measurement have been developed. Since accurate $\mathbb{R}$ radiation measurement plays a critical role for the success of this project, various instrumentation to measure the radiant output from the infrared burner have been evaluated. An FTIR system 2000 from Perkin Elmer was chosen for its complete emission spectrum measurement capability and its flexibility. FTIR, a black body (to calibrate the FTIR), and associated optics were installed in this quarter and calibration of the FTIR is in progress. An emission duct to collect the flue gas of the burner was also fabricated in this quarter. Measurement of the composition of the gas species exiting the burner for various fuel mixture/air ratios is in progress. Various analytical models to predict the heat output were examined. Physical and theoretical analysis to predict the burner efficiency was formulated. Implementation of a burner code at CAU's computing facility is in progress.

\section{Development of the Experimental Facilities}

\section{Measurement of Radiant Output}

Sathe et al. [1] used a pyroelectric detector (Oriel Model) connected to an Oriel radiometer to measure the radiation from the porous radiant burner. Sheridan [2] used a thermopile (Eppley Model) connected to a radiometer to measure the radiant output from a tube heater. Williams et al. [3] employed an optical pyrometer to measure the total radiation output from surface burners. Though these techniques are inexpensive, they do - not provide a detailed spectrum of intensity versus wavelengths. Such a spectrum will indicate at which wavelength a load best absorbs heat and how much energy is available at various wavelengths. Also, it will help to match the burner emission to load absorption for optimum process efficiency.

An FTIR spectrometer such as System 2000 from Perkin Elmer provides such measurement capability. Solomon et al.[4] demonstrated the use of FTIR technique in the measurement of emission output and concentration of gaseous species in their coal combustion experiments. They validated the FTIR measurements with independent thermocouple measurements made at the same point. It should be noted that Kawaguchi et al. [5] employed a monochrometer (SR-5000 made by CI Co) to measure the emissive power from a heated mat. But the wavelength range employed in this monochrometer is only from 1.3 to 14.5 micrometers. System 2000 with a $\mathrm{KBr}$ detector will provide a wavelength range of about 1 to 25 micrometers. Further, it can be upgraded for any range of wavelength as necessary in the future. Furthermore, System 2000 is versatile that it's use can be expanded and configured with a GC-IR interface, TG-IR interface, FT-IR microscope, and NIR FT-Raman accessory. 
A blackbody with a temperature range of 50 to 1200 degree C (model IR-564 from Graseby Infrared) was employed to calibrate the FTIR. Positioning and alignment of a parabolic right angle mirror to transmit the infrared source from a known area of the burner to the emission port of the FTIR is in progress (see Figure 1a).

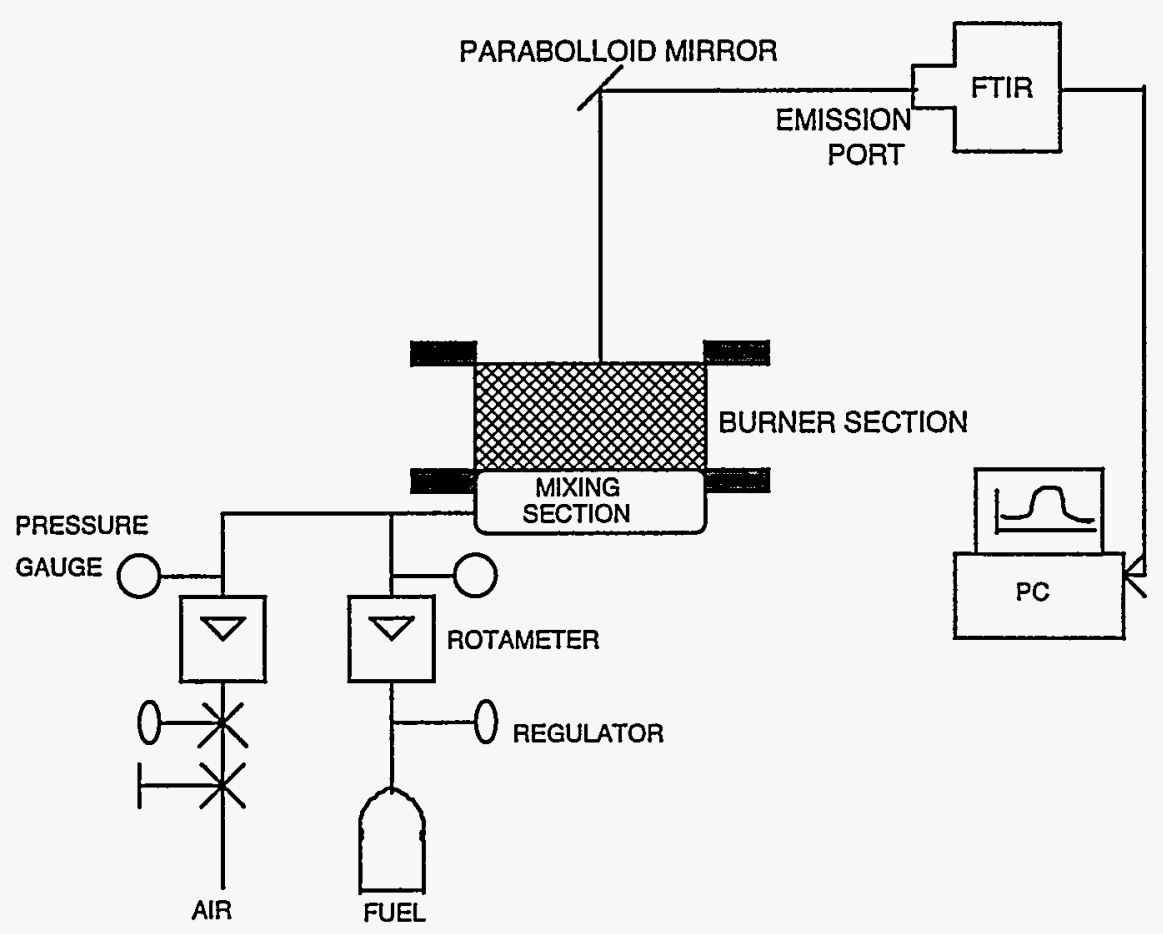

Figure 1a: Schematic Diagram of Radiation Measurement System

The burner is replaced with the blackbody during calibration. The blackbody is set at a known temperature and the emission is measured by the FTIR. The resultant curve of relative intensity versus wavelength represents the spectral distribution of the radiant energy. The area under the curve represents the total normal radiation emitted by the blackbody at the set temperature. The relative intensity at the peak height represents the peak emittance of the blackbody at the set temperature. The experiment is repeated for an increment of 50 degrees in temperature from 50 to 1200 degree C. A calibration equation for radiant output as a function of spectrum area is then developed. Using this equation, the energy radiated by the porous burner for various fuel compositions can be determined with the FTIR without actually knowing the temperature or emissivity of the burner.

\section{Measurement of Emission Species}

An exhaust manifold is being designed and fabricated to collect emission gas from the burner surface for analysis (see Figure 1b). The exhaust section will be kept cooled and maintained at a constant heat-sink temperature. Various gas mixtures of known volume fraction of methane and propane will be burnt for various fuel/air 
stoichiometric ratios ranging from 0.5 to 1.5 . The effect of feed gas compositions on the composition of the flue gas will then be analyzed for $\mathrm{NO}_{x} / \mathrm{SO}_{x}$ and unburnt hydrocarbon using a Horiba gas analyzer. The gas analyzer is calibrated using gases of known composition.

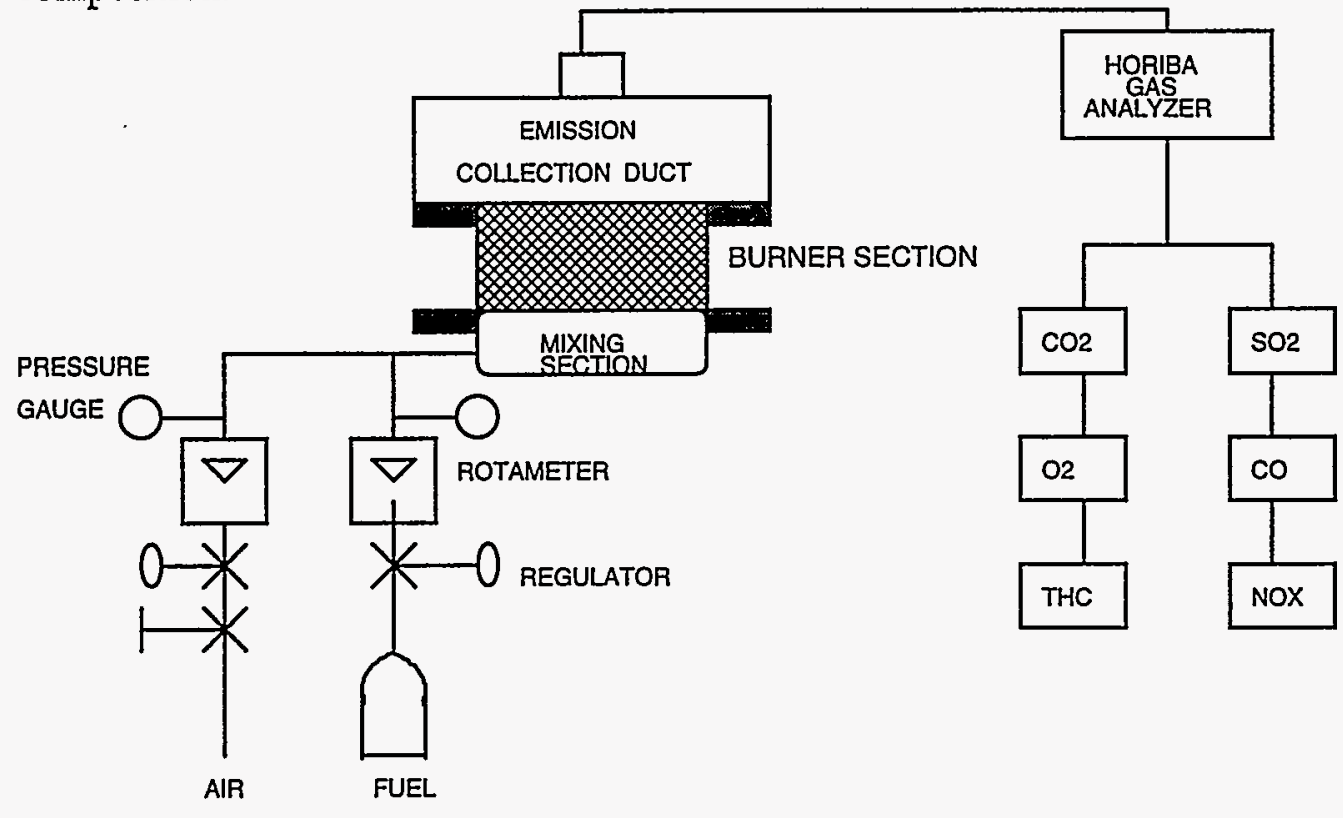

Figure 1b: Schematic Diagram of Emission Measurement System

\section{PIR Burner Performance Model Development}

Applications of the radiant burners include boilers, air heaters, deep fat fryers, process heaters, and immersion heaters. One main reason for the present interest in this type of burner is its low $\mathrm{NO}_{\mathrm{x}}$ emissions. This is attributed to the fact that a large proportion of the heat of combustion is given out as radiation from the burner surface. This results in relatively low gas temperature in the combustion zone compared to that of a conventional free-flame burner. As a consequence, such burners produce less $\mathrm{NO}_{\mathrm{x}}$ mainly by the so called prompt-NO mechanism [3].

In service, infrared burners have had reliability and performance problems, especially when exposed to various gas compositions, operating altitudes, and other ambient conditions like temperature and humidity. These parameters also effect the composition of the gaseous emissions from these burners. In this program, the theoretical basis for the behavior of these burners to the change in the above parameters will be established through analysis of the combustion, heat and mass transfer, and other related processes. For this, an in-depth review of the existing models [1,5-9] is conducted. This review yielded specific direction and recommendations to suitably modify one of the existing codes [1] to meet our need. 
Sathe et al. [1] modified the PREMIX code developed by Kee et al. [10]. PREMIX predicts the combustion behavior of steady laminar one-dimensional premixed flames. Sathe et al. [1] modified the code to predict the combustion behavior of porous burners by including the energy equation for the finite solid phase of the burner. Reitz et al.[11] modeled the methane-air oxidation using a one-step irreversible reaction. Sathe et al. [1] used the Arrhenius type rate constant provided by Reitz et al. [11] in their analysis. In the present analysis, the model developed by Sathe et al. [1] will be modified to predict the behavior of the burner for the oxidation of various fuel gas compositions including the mixture of methane and propane. Also, the model will be modified to predict the burner performance to changes in the ambient conditions of temperature, humidity, and barometric pressure.

The principle of the infrared burner is as follows: A mixture of air and fuel gas enters a highly porous ceramic or metal layer of approximately $10 \mathrm{~mm}$ thick ( $\mathrm{L}$ in Figure 2); the mixture is gradually heated inside the layer and combusted, while it is flowing through the layer. The combustion takes place within the layer at some $5 \mathrm{~mm}$ thick $\left(\mathrm{x}_{\mathrm{f}}\right.$ in Figure 2). The enthalpy of combustion released in the gas phase heats the porous matrix which then emits thermal radiation to a heat load.

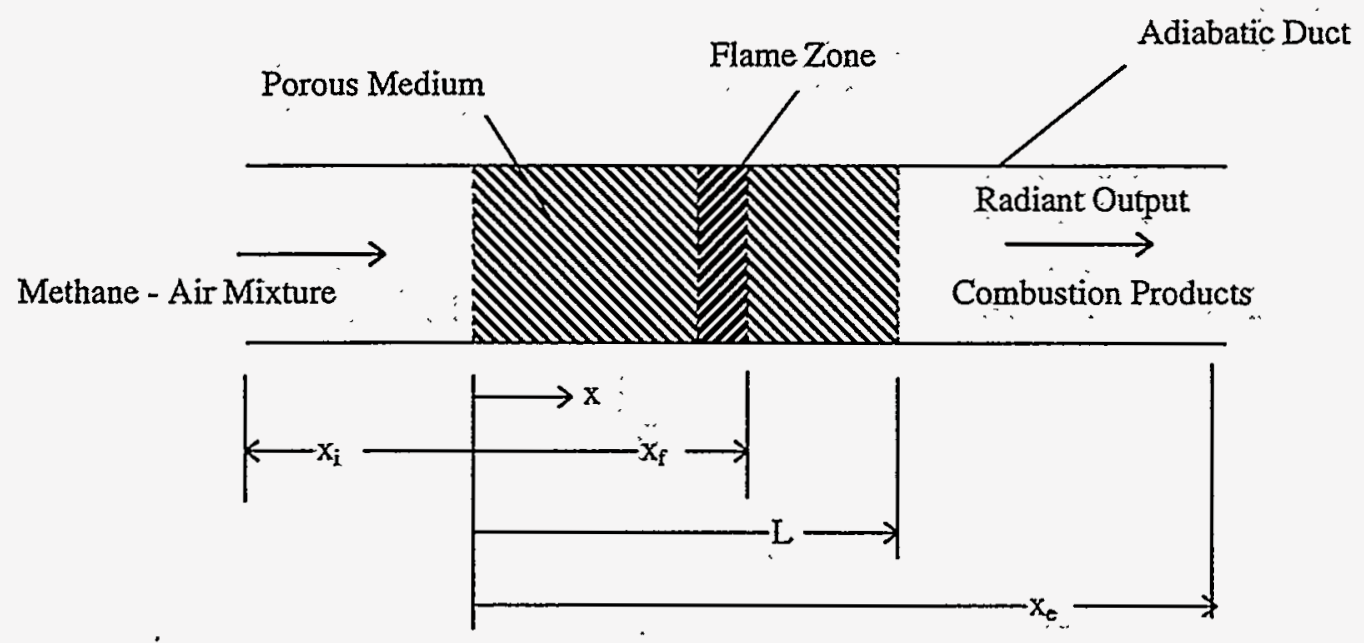

Figure 2. One-Dimensional Model for combustion in the Porous Radiant Burner.

The constitutive equations describing the one-dimensional, steady-state, isobaric combustion process in the burner are as follows [1]:

Continuity Equation:

$$
\frac{d}{d x}(\rho u \phi)=0
$$

where $\phi$ is the porosity of the medium. For identification of other symbols, see nomenclature. 
Species Conservation Equation:

$\rho u \phi \frac{d Y_{k}}{d x}+\frac{d}{d x}\left(\rho \phi Y_{k} V_{k}\right)=\phi \dot{\omega}_{k} W_{k}(k=1, K)$

where $V_{k}$ is the diffusion velocity and is the sum of the diffusion velocities due to mole fraction gradients and the thermal gradients $[10] ; \dot{\omega}_{k}$ is the rate of fuel-air oxidation.

Gas Energy Equation:

$$
\begin{array}{r}
\rho u \phi c_{g} \frac{d T_{g}}{d x}+(1-\phi) h a\left(T_{g}-T_{s}\right)+\phi \sum_{k=1}^{K} \rho Y_{k} V_{k} C_{k} \frac{d T_{g}}{d x} \\
=-\phi \sum_{k=1}^{K} \dot{\omega}_{k} h_{k} W_{k}+\frac{d}{d x}\left(\phi k_{g} \frac{d T_{g}}{d x}\right)
\end{array}
$$

Solid Energy Equation:

$$
\frac{d}{d x}\left[(1-\phi) k_{s} \frac{d T_{s}}{d x}\right]+(1-\phi) h d\left(T_{g}-T_{s}\right)=\frac{d q^{r}}{d x}
$$

where the radiative heat flux

$$
q^{r}=2 \pi \int_{-1}^{1} i\left(x, \mu^{\prime}\right) d \mu^{\prime}
$$

Radiative Transfer Equation (RTE):

$$
\mu \frac{\partial i(x, \mu)}{\partial x}+\left(\sigma_{a}+\sigma_{s}\right) i(x, \mu)=\sigma_{a} i_{b}\left(T_{s}\right)+\frac{\sigma_{s}}{2} \int_{-1}^{1} i\left(x, \mu^{\prime}\right) d \mu^{\prime}
$$

where $\mu^{\prime}$ is the dummy variable of integration and $i_{b}\left(T_{s}\right)=\sigma T_{s}^{4} / \pi$

Equation of State:

$$
\rho=\frac{\bar{W} p}{R T_{g}}
$$

Boundary Conditions:

The gas temperature and the species concentrations are known at the inlet section at $\mathrm{X}=-\mathrm{X}_{\mathrm{i}}$. Thus,

$$
\begin{aligned}
& Y_{k}=Y_{k, i .} \quad T_{g}=T_{i} \text { at } x=-x_{i} \\
& \frac{d Y_{k}}{d x}=\frac{d I_{g}}{d x}=0 \text { at } x=x_{e}
\end{aligned}
$$

The boundary conditions to predict the solid temperature are written assuming that the solid loses heat to the gas by convection such that

$$
-k_{s} \frac{d T_{s}}{d x}=h\left(T_{g}-T_{s}\right) \quad \text { at } x=0, \text { and } k_{s} \frac{d T_{s}}{d x}=h\left(T_{g}-T_{s}\right) \text { at } x=L
$$


The upstream boundary condition to predict the radiant intensity is written assuming that the emitting surface is a gray body and the downstream boundary condition assuming that the burner is seeing a black environment at $T_{b}=298 \mathrm{~K}$ :

$$
\begin{aligned}
& i^{+}(0)=\varepsilon i_{b}\left(T_{i}\right)+r_{d} \int_{-1}^{1} i^{-}\left(0,-\mu^{\prime}\right) \mu^{\prime} d \mu^{\prime} \text { at } x=0, \text { and } \\
& i^{-}(L)=i_{b}\left(T_{b}\right) \text { at } x=L
\end{aligned}
$$

Solution Procedure:

PREMIX [10] employs finite-difference technique with adaptive gridding and solve the set of nonlinear constitutive equations by the damped Newton Rapshon method. Sathe et al. [1] simplified the code using spherical harmonic approximation for the radiative transfer equation (RTE). The time required to solve for one set of parameters on an IBM computer ranges from approximately $100-500 \mathrm{cpu}$ seconds, depending on the initial guess provided [1].

The numerical code developed by Sathe et al. [1] will be modified to predict the burner behavior to the changes in fuel gas compositions and other ambient conditions.

\section{PLANS FOR THE NEXT QUARTER}

The following short term tasks are planned to accomplish during the next quarter:

1. The parabolic mirror to collect and transmit radiation from the burner has a focal length of about $160 \mathrm{~mm}$. It views a small spot at the surface of the burner at about $174 \mathrm{~mm}$. The transmission efficiency of the mirror to this configuration is greater than 99\%. Since such a small distance in between, heat shields will be installed below the mirror and a fan will be positioned behind the mirror to protect it from damage due to excessive heat from the burner. Design, fabrication, and positioning of heat shields will be completed shortly.

2. Calibration of the FTIR against the standard blackbody source, without and with the mirror in place, will be completed within November ' 95 . In addition to the development of calibration equations, the data will be used to assess and correct for the transmission efficiency of the mirror.

3. A test matrix for various gas mixtures of known volume fraction of methane and propane will be developed. The range of fuel/air stoichiometric ratios to be studied for each gas mixture will be included in the matrix. Following the development of the test matrix, actual radiation measurements will be initiated and about $25 \%$ of the experiments planned in the test matrix will be completed by the end of the next quarter.

4. Modification, fabrication and installation of the exhaust section of the burner will be completed shortly. Initial runs of emission gas measurements will be completed by the end of next quarter. 
5. Implementation of a radiant burner numerical code at CAU's computing facility will be completed within next quarter. Following the implementation, the model will be interfaced with CAU's graphics package. Sensitivity analysis will be carried out to identify key parameters of the model and sensitivity plots generated.

\section{SUMMARY AND CONCLUSIONS}

In summary, the project is progressing well. The scheduled tasks for this period of time are conducted smoothly. Specifically:

1. System 2000, an FTIR instrument from Perkin Elmer, and a black body from Graseby Infrared to calibrate the FT-IR are installed in the porous burner radiant measurement system and the calibration of the FTIR is in progress. Following the calibration, the spectral radiant output of the burner will be measured for various fuel compositions and ambient conditions. The exhaust gas measurement system is tested and the actual flue gas measurement and analysis is in progress.

2. Theoretical analysis and formulation of the PIR burner performance model are formulated and the implementation of a numerical code at CAU's computing facility is in progress.

\section{Nomenclature}

c

$\mathrm{Nu}$

$p$ surface area per volume of solid $[1 / \mathrm{m}]$

specific heat capacity at constant pressure [J/kg-K]

diameter [m]

heat transfer coefficient $\left[\mathrm{W} / \mathrm{m}^{2}-\mathrm{K}\right]$

species specific enthalpy $[\mathrm{J} / \mathrm{kg}]$

radiant intensity $\left[\mathrm{W} / \mathrm{m}^{2}-s r \quad\right]$

thermal conductivity $[\mathrm{W} / \mathrm{m}-\mathrm{K}]$

porous layer length $[\mathrm{m}]$

Nusselt number

pressure $\left[\mathrm{N} / \mathrm{m}^{2}\right]$

radiant heat flux $\left[\mathrm{W} / \mathrm{m}^{2}\right]$

extinction efficiency

reflectivity

universal gas constant [J/mole-K]

Reynolds number

temperature [K]

axial velocity $[\mathrm{m} / \mathrm{s}]$

diffusion velocity $[\mathrm{m} / \mathrm{s}]$

molecular weight $[\mathrm{kg} / \mathrm{mole}]$

average molecular weight $[\mathrm{kg} / \mathrm{mole}]$

axial coordinate [m]

mass fraction 


\section{Greek Symbols}

$\begin{array}{ll}\varepsilon & \text { emissivity } \\ \mu & \text { direction cosine in Eq. (5) } \\ \rho & \text { gas density }\left[\mathrm{kg} / \mathrm{m}^{3}\right] \\ \sigma & \text { Stefan Boltzmann constant }\left[\mathrm{W} / \mathrm{m}^{2}-\mathrm{K}^{4}\right] \\ \sigma_{a}, \sigma_{s}, \sigma_{e} & \text { absorption, scattering and extinction coefficients }[1 / \mathrm{m}] \\ \tau & \text { optical depth, } \sigma_{e} \mathrm{~L} \\ \phi & \text { porosity } \\ \Phi & \text { equivalent ratio } \\ \dot{\omega} & \text { molar generation rate }\left[\text { moles } / \mathrm{m}^{3}-\mathrm{s}\right] \\ \omega & \text { scattering albedo } \sigma_{s} / \sigma_{e}\end{array}$

Superscipts

$\begin{array}{ll}+ & \text { positive direction } \\ - & \text { negative direction } \\ r & \text { radiation }\end{array}$

Subscripts

$\begin{array}{ll}b & \text { blackbody } \\ c & \text { combustion } \\ d & \text { diffuse,downstream } \\ e & \text { exit plane } \\ f & \text { flame } \\ g & \text { gas } \\ i & \text { inlet plane } \\ k & \text { index for species } \\ s & \text { solid }\end{array}$

\section{REFERENCES}

1. Sathe, S. B., Kulkarni, M. R., Peck, R. E., and Tong, T. W., An Experimental and Theoretical Study of Porous Radiant Burner Performance. Twenty-Third Symposium (International) on Combustion/The Combustion Institute, 1990/pp. 1011-1018.

2. Sheridan, R., Determination of Radiant Output from Infrared Tube Heaters, GRI Topical Report, May 1994.

3. Williams, A., Woolley, R., and Lawes, M., The Formation of NO $\underline{x}$ in Surface Burners, Combustion and Flame 89: 157-166 (1992). 
4. Solomon P. R., Serio, M. A., Carangelo, R. M., and Markham, J.R., Very Rapid Coal Pyrolysis, 1986, Fuel 65, 182.

5. Kawaguchi, O., Otoh, T., Nakamura, S., Todoroki, A., and Murayama,Y., Premixed Combustion at a Fiber Mat, Twenty-Third Symposium (International) on Combustion/The Combustion Institute, 1990/pp. 1019-1024.

6. Sathe, S. B., Peck, R. E., and Tong, T. W., Flame Stabilization and Multimode Heat Transfer in Inert Porous Media: A Numerical Study,Combust. Sci. and Tech., 1990, vol.70, pp. 93-109.

7. Andersen, F., Heat Transport Model for Fiber Burners. Prog. Energy Combust. Sci., 1992. Vol. 18, pp. 1-12.

8. Sathe, S. B., Peck, R. E., and Tong, T. W., A Numerical Analysis of Heat Transfer and Combustion in Porous Radiant Burners. Intl. J. Heat and Mass Transfer, Vol. 33, No. 6, pp.1331-1338, 1990.

9. Yoshizawa, Y., Sasaki, K., and Echigo, R., Analytical Study of the Structure of Radiation Controlled Flame, Intl. J. Heat and Mass Transfer, Vol. 31, No. 2, pp. 311-319, 1988.

10. Kee, R. J., Grcar, J. F., Smooke, M.D., and Miller, J.A.: A Fortran Program for modeling Steady Laminar One Dimensional Premixed Flames, Sandia National Laboratory Report SAND85-8240, 1985.

11. Rreitz, R. D. and Bracco, F. V.: Numerical Methods in Laminar Flame Propagation. (N. Peters and J. Warnatz, Eds, ), p.130, Vieweg, 1982. 